\title{
OBSERVATIONS ON THE POLARON MODEL FOR GENETIC RECOMBINATION
}

\author{
D. R. STADLER \\ Department of Genetics, University of Woshington, \\ Seattle 5, Woshington
}

Received 21.xi.62

\section{INTRODUCTION}

IN I955 Mary Mitchell exploded the long-accepted myth that genetic recombination was brought about by precisely-reciprocal exchanges between homologous chromosomes. Until then it had been believed that any given segment of a chromosome going into meiosis would be represented in two of the products, the other two deriving their information from the corresponding segment of the homologue. Mitchell demonstrated that a very short region may have a $3: \mathrm{I}$ ratio of the parent types, with the normal (reciprocal) $2: 2$ ratio re-established at closely-linked marker loci on both sides. The same study revealed that the exchange events involved in recombination must frequently be more complex than the single crossovers which had provided a satisfactory accounting for earlier observations. The mechanism of chromosomal recombination has since become a lively field of investigation, but this work has suffered a heavy burden of frustration.

Non-reciprocality can only be demonstrated by recovering all the products of a tetrad. Tetrad analysis has been done extensively in some ascomycetes, and it normally requires dissection, isolation and growth of the ascospores before they can be classified for genetic characteristics. Since the non-reciprocal segments are very short and widely spaced, they occur only rarely at any given locus. Thus Mitchell dissected 988 asci of Neurospora in order to detect four which had non-reciprocal recombination at the locus of the genes for pyridoxine requirement. Very laborious studies of this kind have yielded rather meagre data, and, sadly, they have not been rewarded with results that make a nice fit to any simple and attractive model. As a result, there was double reason for joy at the appearance of the studies of Lissouba, Rizet and their co-workers (Rizet et al., 1960; Lissouba, I960; Lissouba et al., 1962) on recombination between spore mutants of Ascobolus. They have analysed several hundred tetrads with non-reciprocal recombination, and they have beautifully accounted for their results with a simple hypothesis based on a structure with the compelling name of " polaron".

\section{RECOMBINATION IN ASCOBOLUS-THE POLARON MODEL}

These workers have isolated some 2000 mutant strains with altered pigmentation of the ascospores. Those which have been studied extensively all have the same phenotype : unpigmented spores. Wildtype spores are black. A cross of any of these mutants to wildtype 
gives asci with the segregation characteristic of a single gene-pair : four black spores and four white ones. A cross between two mutants can only give black spores by recombination. By observing asci from these crosses, they have been able to group the mutants into a number of "series" of closely-linked sites. A cross between two mutants of the same series gives infrequent recombination-most of the asci have eight colourless spores, while the remainder have two black spores and six colourless ones. The latter are the recombination asci, and their frequency may be used as a measure of the genetic distance between the two mutant sites.

Let us consider series 46 , on which the information is most complete. Fig. I shows the genetic map of these mutants based on the frequencies of recombination $(2: 6)$ asci in the crosses between various pairs of the mutants. The figures are not so precisely additive as to demand

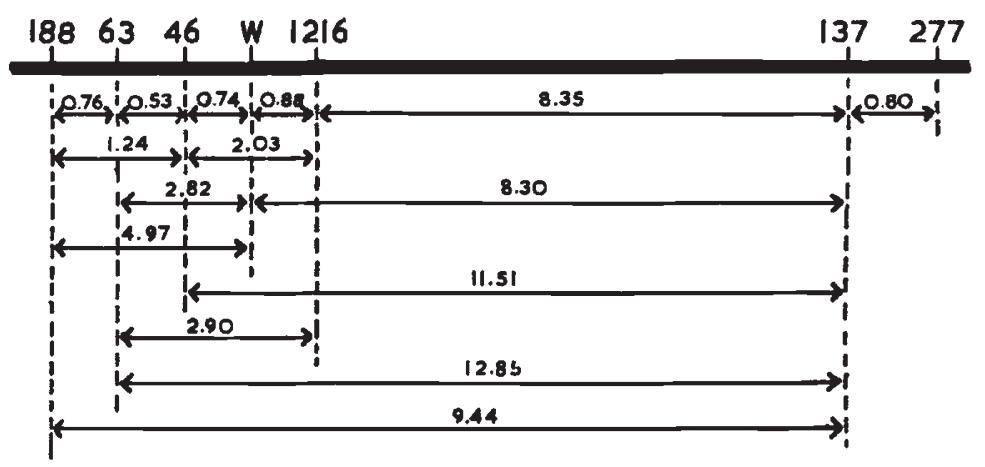

Fig. 1.-Relative positions of mutant sites of series 46 as determined by the frequencies of $2: 6$ asci per 1000 . From Lissouba et al., 1962 .

the specific order of sites as shown here, but it is clear that they are compatible with this order.

The most important finding in this study comes from the analysis of the recombination asci from these crosses between two mutants of the same series. In each ascus the three pairs of mutant spores have been classified by backcrosses to both parents. When any of these mutants is selfed (crossed to another strain derived from the same mutant), no black spores are found even in many thousands of asci. The backcross test permits the distinction of the two mutants from each other and from the double mutant (see table I).

Table 2 shows the analysis of recombination asci in crosses between mutants of series 46 (excluding 277). The event giving rise to the wildtype recombinant has been non-reciprocal in every case (one doubtful exception in a total of 155 asci). This could result from a non-reciprocal $(3: \mathrm{I})$ ratio at either mutant locus. However, in any given cross the site of the non-reciprocal event (the minority parent) turns out to be the same in every ascus analysed. Furthermore, for any pair of mutants crossed, it is always the mutant to the right in the genetic map (fig. I) which is the consistent minority parent. 
TABLE I

Method of classification of recombinant asci in crosses between white-spored mutants of Ascobolus

$$
m \mathrm{I} \times m 2 \quad \frac{m \mathrm{I} \quad}{\overline{+} m_{2}}
$$

Reciprocal recombination ascus :

\begin{tabular}{|c|c|c|c|c|c|}
\hline \multirow{2}{*}{$\begin{array}{l}\text { Spore } \\
\text { pair }\end{array}$} & \multirow{2}{*}{ Colour } & \multirow{2}{*}{$m \mathrm{I}$} & \multirow{2}{*}{$m 2$} & \multicolumn{2}{|c|}{$\begin{array}{c}\text { Backcross test } \\
\text { (production of recombinants) }\end{array}$} \\
\hline & & & & $\times m \mathbf{I}$ & $\times m 2$ \\
\hline 1 & Black & + & + & $\ldots$ & $\ldots$ \\
\hline 2 & White & $m_{\mathrm{I}}$ & + & - & + \\
\hline 3 & White & + & $m 2$ & + & - \\
\hline 4 & White & $m \mathrm{I}$ & $m 2$ & - & - \\
\hline
\end{tabular}

Non-reciprocal recombination ascus :

\begin{tabular}{|c|c|c|c|c|c|}
\hline \multirow{2}{*}{$\begin{array}{c}\text { Spore } \\
\text { pair }\end{array}$} & \multirow{2}{*}{ Colour } & \multirow{2}{*}{$m_{1}$} & \multirow{2}{*}{$m 2$} & \multicolumn{2}{|c|}{ Backcross test } \\
\hline & & & & $\times m_{\mathbf{I}}$ & $\times m 2$ \\
\hline $\begin{array}{l}1 \\
2 \\
3 \\
4\end{array}$ & $\begin{array}{l}\text { Black } \\
\text { White } \\
\text { White } \\
\text { White }\end{array}$ & $\begin{array}{c}+ \\
m_{1} \\
+ \\
m_{\mathrm{I}}\end{array}$ & $\begin{array}{c}+ \\
+ \\
m 2 \\
+\end{array}$ & $\begin{array}{l}\cdots \\
+\end{array}$ & $\frac{\dddot{t}}{+}$ \\
\hline
\end{tabular}

TABLE 2

Genetic analysis of $2: 6$ asci in crosses between mutants of series 46 .

(From Lissouba et al., 1962)

\begin{tabular}{|c|c|c|c|c|c|}
\hline \multirow{2}{*}{ Cross } & \multirow{2}{*}{$\begin{array}{l}\text { No. of } 2: 6 \\
\text { asci analysed }\end{array}$} & \multirow{2}{*}{$\begin{array}{c}\text { Reciprocal } \\
\text { recombination }\end{array}$} & \multirow{2}{*}{$\begin{array}{l}\text { Non-reciprocal } \\
\text { recombination }\end{array}$} & \multicolumn{2}{|c|}{ Parent } \\
\hline & & & & majority & minority \\
\hline $\begin{array}{l}188 \times 63 \\
188 \times 46 \\
188 \times W \\
188 \times 138\end{array}$ & $\begin{array}{r}8 \\
2 \\
10 \\
11\end{array}$ & $\begin{array}{l}0 \\
0 \\
0 \\
0\end{array}$ & $\begin{array}{r}8 \\
2 \\
10 \\
11\end{array}$ & $\begin{array}{l}188 \\
188 \\
188 \\
188\end{array}$ & $\begin{array}{c}63 \\
46 \\
W \\
138\end{array}$ \\
\hline $\begin{array}{l}\sigma_{3} \times 4{ }^{6} \\
\sigma_{3} \times W \\
\sigma_{3} \times 1216 \\
\sigma_{3} \times 13^{8}\end{array}$ & $\begin{array}{r}2 \\
18 \\
5 \\
35\end{array}$ & $\begin{array}{l}0 \\
0 \\
1 ? \\
0\end{array}$ & $\begin{array}{r}2 \\
18 \\
4 \\
35\end{array}$ & $\begin{array}{l}6_{3} \\
63 \\
63 \\
63\end{array}$ & $\begin{array}{r}46 \\
W \\
1216 \\
13^{8}\end{array}$ \\
\hline $\begin{array}{l}46 \times W \\
46 \times 13^{8}\end{array}$ & $\begin{array}{r}7 \\
22\end{array}$ & $\begin{array}{l}\text { o } \\
\text { o }\end{array}$ & $\begin{array}{r}7 \\
22\end{array}$ & $\begin{array}{l}46 \\
46\end{array}$ & $\begin{array}{r}W \\
13^{8}\end{array}$ \\
\hline $\begin{array}{l}W \times 1216 \\
W \times 13^{8}\end{array}$ & $\begin{array}{l}18 \\
15\end{array}$ & $\begin{array}{l}\mathbf{o} \\
\mathbf{o}\end{array}$ & $\begin{array}{l}18 \\
15\end{array}$ & $\underset{W}{W}$ & $\begin{array}{r}1216 \\
13^{8}\end{array}$ \\
\hline $1216 \times 137$ & 2 & o & 2 & 1216 & 137 \\
\hline Total & 155 & $1 ?$ & 154 & & \\
\hline
\end{tabular}

Note: Mutant $13^{8}$ is believed to be identical to 137 . 
Lissouba and Rizet have explained this result in terms of a polaron -a structural region for recombination. They envisage non-reciprocal recombination as the result of a polarised copy-error (fig. 2). The two new strands formed in meiosis must copy off opposite homologues as they start along the polaron from left to right. Copy-errors occur as the result of a switch of one strand to the opposite template. From

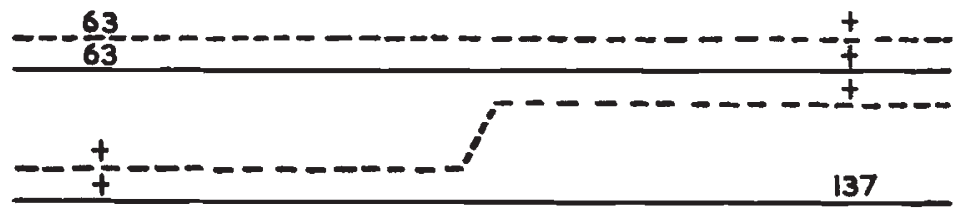

FIG. 2.-Non-reciprocal recombination between two mutant sites in the same polaron, according to the hypothesis of Lissouba et al.

the point of switch to the right-hand end of the polaron, both new strands copy the same homologue. In a cross between two mutants located in the same polaron, recombination can only occur by a non-reciprocal switch between the two sites, and the mutant to the right will segregate $3: \mathrm{I}$. Thus the authors conclude that mutant

TABLE 3

Genetic analysis of $2: 6$ asci in crosses of mutant 277 to other mutants of series 46 .

(From Lissouba et al., 1962)

\begin{tabular}{|c|c|c|c|c|c|}
\hline \multirow{2}{*}{ Cross } & \multirow{2}{*}{$\begin{array}{l}\text { No. of } 2: 6 \\
\text { asci analysed }\end{array}$} & \multirow{2}{*}{$\begin{array}{l}\text { Reciprocal } \\
\text { recombination }\end{array}$} & \multicolumn{3}{|c|}{ Non-reciprocal recombination } \\
\hline & & & $\begin{array}{l}\text { No. of } \\
\text { asci }\end{array}$ & $\begin{array}{l}\text { Majority } \\
\text { parent }\end{array}$ & $\begin{array}{l}\text { Minority } \\
\text { parent }\end{array}$ \\
\hline $\begin{array}{r}63 \times 277 \\
46 \times 277 \\
W \times 277 \\
1216 \times 277\end{array}$ & $\begin{array}{r}11 \\
6 \\
12 \\
8\end{array}$ & $\begin{array}{l}4 \\
0 \\
2 \\
0\end{array}$ & $\begin{array}{r}7 \\
6 \\
10 \\
8\end{array}$ & $\begin{array}{c}63 \\
46 \\
W \\
1216(6) \\
277(2)\end{array}$ & $\begin{array}{c}277 \\
277 \\
277 \\
277(6) \\
1216(2)\end{array}$ \\
\hline $137 \times 277$ & 17 & o & 17 & $\begin{array}{l}277(16) \\
137(1)\end{array}$ & $\begin{array}{l}137(16) \\
277(1)\end{array}$ \\
\hline Total & 54 & 6 & $4^{8}$ & & \\
\hline
\end{tabular}

sites $188,63,46, W, 1216$ and 137 are all located in the same polaron.

The crosses of these mutants to mutant strain 277 give a different result (table 3). The recombination asci include both the reciprocal and non-reciprocal type. Among the non-reciprocals the rule of the consistent minority parent is violated. The authors conclude that the site of 277 is in a separate polaron, and that a "linkage structure" separates the two. This structure is the site of reciprocal recombination. It is also possible for a copy-error strand to return to its original 
template at the linkage structure (see fig. 3), and this event would account for those non-reciprocal recombination asci in which the mutant to the right (277) is the majority parent. It may be noted that nearly all the recombination asci in the cross of $137 \times 277$ are of this type, as might be expected if the two mutants are very close together on opposite sides of the linkage structure.

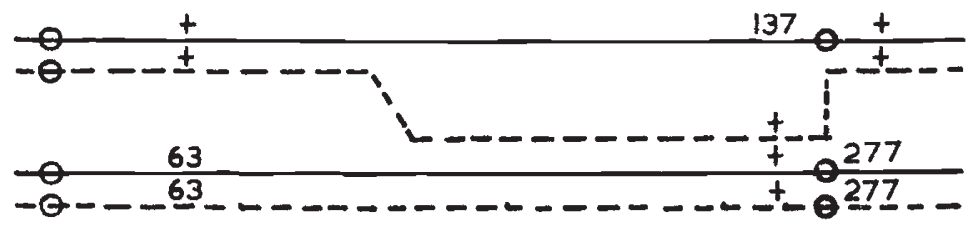

FIG. 3.-Correction of a copy-error at the linkage structure. This "return" results in non-reciprocal recombination between the mutant sites embracing the linkage structure.

Two aspects of the data on recombination of 277 appear to conflict with the linkage map, but they are nicely explained by the model. The amount of recombination in crosses of 277 to mutants on the left is generally slightly lower than in the crosses of 137 to the same mutants (table 4). Also, the 3-point cross $137 \times 63$-277 yields wild-type recombinants with the same frequency as the cross $137 \times 277$. Both these

TABLE 4

Comparison of frequencies of $2: 6$ asci (per thousand) in crosses of various mutants of series 46 with $\mathrm{I} 37$ and with 277 . (From Lissouba et al., 1962)

\begin{tabular}{|c|c|c|c|c|c|}
\hline & $\times 137$ & $\times 277$ & & $\times 137$ & $\times 277$ \\
\hline 1604 & $20 \cdot 84 \pm I \cdot I I$ & $13.55 \pm 1 \cdot 12$ & $x+67$ & $5 \cdot 76 \pm 0 \cdot 86$ & $4.87 \pm 0.54$ \\
\hline 1546 & $18 \cdot 17 \pm 1 \cdot 23$ & $12.53 \pm 1.02$ & 686 & $7.56 \pm 0.71$ & $5 \cdot 43 \pm I \cdot 2 I$ \\
\hline 188 & $9 \cdot 33 \pm 1 \cdot 04$ & $7.50 \pm 2.47$ & $144^{16}$ & $7 \cdot 56 \pm 1 \cdot 06$ & $4.23 \pm 0.56$ \\
\hline 63 & $12.85 \pm 2 \cdot 47$ & $14.50 \pm 0.96$ & $W$ & $8 \cdot 30 \pm 0.67$ & $9 \cdot 88 \pm I \cdot 43$ \\
\hline 665 & $9 \cdot 79+I \cdot 4 I$ & $13.53 \pm 1 \cdot 52$ & 1216 & $8 \cdot 35 \pm 0 \cdot 47$ & $6 \cdot 84+1 \cdot 10$ \\
\hline 1330 & $9 \cdot 18 \pm 1 \cdot 59$ & $8 \cdot 26 \pm 1 \cdot 08$ & 1021 & $2 \cdot 25 \pm 0 \cdot 39$ & 0.9 I $(0.62$ to 1.33$)$ \\
\hline $4^{6}$ & $I I \cdot 5 I \pm I \cdot I 5$ & $10 \cdot 06 \pm 1 \cdot 25$ & 1026 & $2 \cdot 13 \pm 0 \cdot 18$ & $0.79(0.60$ to $\mathrm{I} .03)$ \\
\hline
\end{tabular}

Note.-In spite of the high frequencies of recombination in the crosses involving 1604 and 1546 , all these mutants are believed to lie in the interval between 188 and 277 .

findings would lead the conventional genetic map-maker to place 277 to the left of 137 . However, the authors believe that 277 is separated from the other mutants by a linkage structure, and therefore it must lie beyond 137. They point out that the return of a copy-error strand to its own template at the linkage structure would sometimes nullify an event which otherwise would have produced recombination with 277 , thus accounting for the lowered frequencies. In the 3-point cross, they say that wild-type recombinants result from a copy error between $6_{3}$ and 137 and a return at the linkage structure (fig. 3). If mutant site $\sigma_{3}$ is close to the left end of the polaron, nearly all the recombination 
events which give wild-type in the cross of $137 \times 277$ would do so equally well in the cross $137 \times 63-277$.

What is the likelihood that a copy-error strand will return to its own template at the end of the polaron? It cannot be unity, for that would mean that non-reciprocal recombination across the linkage structure $(137 \times 277)$ would be as frequent as between mutants at opposite ends of the polaron $(188 \times 137)$. The authors point out that the chance of return can be directly determined by comparing the

TABLE 5

Determination of the frequency of return of copy-errors at the linkage siructure

\begin{tabular}{|c|c|c|c|c|}
\hline \multicolumn{2}{|c|}{ Crosses } & $\begin{array}{c}f_{1}: \text { frequency of } \\
\text { copy-error } \\
(a \times b \text { recomb. })\end{array}$ & $\begin{array}{c}f_{2}: \text { frequency of } \\
\text { copy-error and } \\
\text { return } \\
(a-c \times b \text { recomb. })\end{array}$ & $\begin{array}{c}\text { Probability } \\
\text { of return } \\
\left(f_{2} / f_{1}\right)\end{array}$ \\
\hline$a \times b$ & $a-c \times b$ & 2.82 & 0.177 & $1 / 16$ \\
$63 \times W$ & $63-277 \times W$ & 12.85 & 0.828 & $1 / 15.5$ \\
\hline $63 \times 137$ & $63-277 \times 137$ & & \\
\hline
\end{tabular}

(Frequencies in this table are per 1000 asci.)

frequency of wildtype recombinants in a two-point cross which requires a copy-error to the frequency in the three-point cross which requires the same copy-error with a return. When this comparison is made in the two cases in which three-point crosses have been performed in series 46 , they both give a frequency of return very close to one-sixteenth (table 5 ).

\section{THE CORRECTION OF COPY-ERRORS}

It is unfortunate that Lissouba and Rizet did not have segregating markers surrounding the spore-colour locus of series 46 , for we should like to know the relationship of the recombination events in these two polarons to the segregation and recombination of outside markers. Other investigators have not analysed so many tetrads with nonreciprocal recombination as have the Ascobolus workers. But there have been sufficient numbers examined in other fungi to establish a rule which cannot be accounted for by the polaron model.

Several dozen tetrads have been analysed in Neurospora in which non-reciprocal recombination took place at a locus which was embraced by closely-linked markers on both sides (Mitchell, I $955 a, b$; Case and Giles, I958a, $b$; Stadler and Towe, unpublished). A recent study on a spore mutant in Sordaria (Kitani, Olive and El-Ani, I 962) reported even larger numbers of asci of this type. In every ascus reported, the non-reciprocal ratio $\left(3: \mathrm{I}_{\text {or }} \mathrm{I}: 3\right)$ at the middle locus is accompanied by a 2:2 segregation for both of the surrounding markers. This means that all copy-errors must be corrected within a 
rather short distance. In the Ascobolus study only one-sixteenth of the copy-errors returned at the end of the same polaron. Where do the others return? It should be observed that the $3:$ I ratio could be restored to $2: 2$ not only by return of the copy-error strand, but also by a switch of the other copying strand. The consequences of a "return" by either strand would be equivalent in the argument that follows.

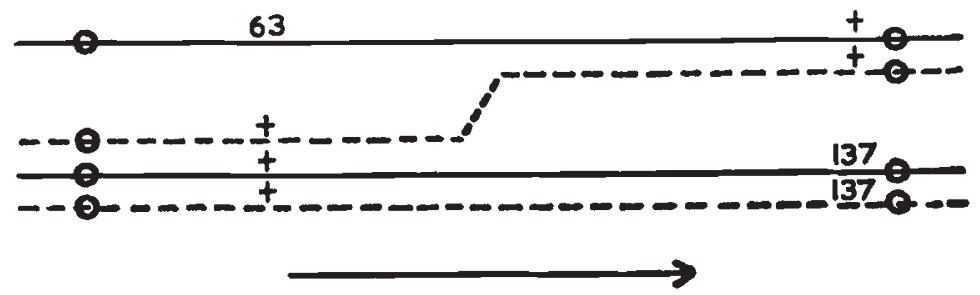
FIG. 4.-A prediction of the polaron model if copy-errors are corrected in subsequent
polarons.

If polarons of the type envisaged by Lissouba and Rizet occur generally, and if these structures are responsible for all normal recombination between homologous chromosomes, they must account for that large fraction of the copy-errors which are not corrected at the terminal end of the polaron in which they occur. They would have to be corrected by a return either along the length of a neighbouring polaron or at a neighbouring linkage structure. Either of these occurrences would lead to results which are not compatible with the observations in series 46 .

If a copy-error established in one polaron could be corrected in a subsequent one, it would lead to non-reciprocal recombination between mutants in the same polaron with the majority parent on the right (fig. 4). This would violate the observation which was fundamental to the model.

If copy-errors which went uncorrected at the first linkage structure were corrected at subsequent linkage structures, the number of returns at any one linkage structure would be equal, on the average, to the total number of copy-errors established in any one polaron. This would lead to two predictions (see fig. 5) :

(I) The frequency of recombination between sites just across the linkage structure from each other $(137 \times 277)$ should be equal to the frequency between sites at the extreme ends of the same polaron $(188 \times 137)$;

(2) The frequencies of recombination between 277 and the mutants to the left should be higher than the frequencies in the crosses of the same mutants to 137 (table 4) by an amount approaching the recombination frequency between 137 and 277 .

While the departure from prediction (2) may possibly be accounted for by statistical fluctuation, prediction ( 1 ) is clearly in conflict with the data. 


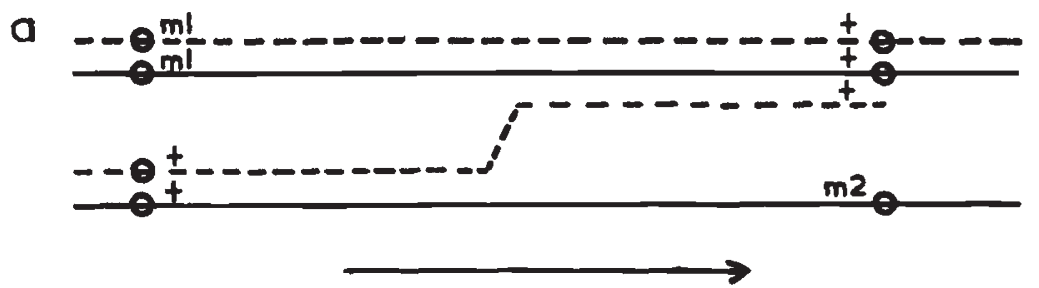

b

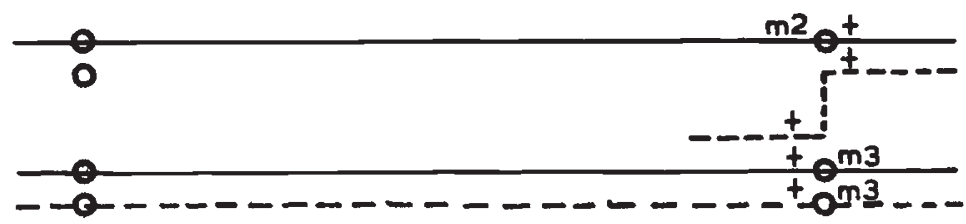

C

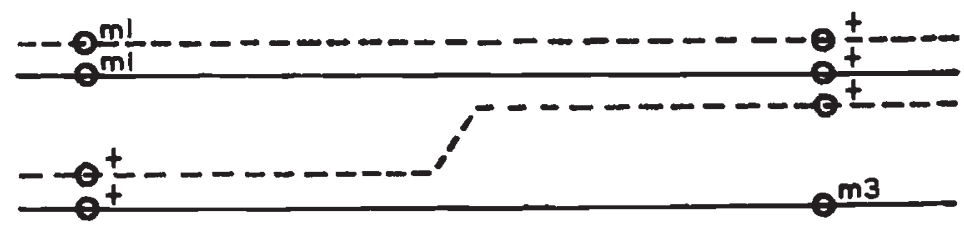

$d$

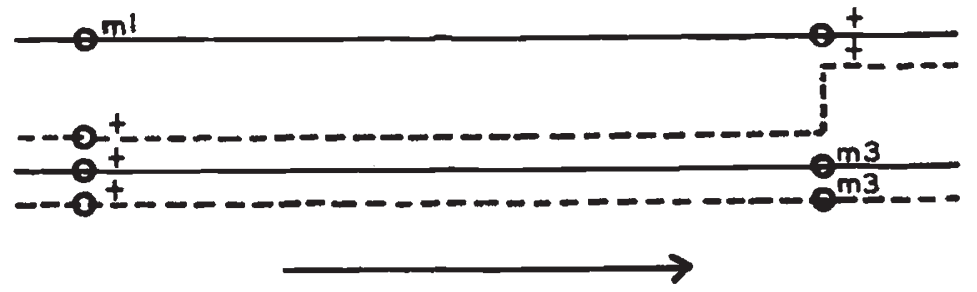

Fic. 5.-Predictions of the polaron model if copy-errors are corrected at subsequent linkage structures.

(a) $m_{1} \times m_{2}$ recombination $=n=$ frequency of copy-error in this (average) polaron.

(b) $m 2 \times m_{3}$ recombination $=n=$ frequency of return of copy-error strands at an average linkage structure

(A fraction $f$ of the copy-errors originating in this polaron are returned at the linkage structure at the end of this polaron. The other $(1-f) n$ returns at this linkage structure are of copy-errors originating in preceding polarons. In the data of Lissouba et al., $f=\mathrm{I} / \mathrm{I} 6$.

(c) $m \mathrm{I} \times m_{3}$ recombination by copy-error $=n-f n=(\mathrm{I}-f) n$.

(d) $m_{1} \times m_{3}$ recombination by return $=(1-f) n$. $m_{1} \times m_{3}$ total recombination $=2(\mathrm{r}-f) n$. (When $f$ is small, this approaches $2 n$.) 


\section{DISCUSSION}

The polaron model for recombination gives a very satisfactory account for the observations on spore mutants in Ascobolus. The one striking aspect of this interpretation which throws doubt on its general significance is that the non-reciprocal ratio which originates at a site of recombination very frequently persists beyond the end of the polaron. It has been shown in other forms that non-reciprocal segments are very short, so these persistent copy-errors must be corrected. They cannot be corrected by a return in a neighbouring polaron, because this would lead to a result (fig. 4) which was conspicuously absent from the Ascobolus data. If we conclude that all copy-errors must be corrected at subsequent linkage structures, then the number of copyerrors in an average polaron equals the number of returns at an average linkage structure. This leads to predictions (fig. 5) which are not fulfilled by the Ascolobus data.

One way of salvaging the model would be to conclude that polaron I88-137 is not average, but it would have to be quite extreme. We would have to say that this polaron has sixteen times the average amount of copy-error, or that this linkage structure has only onesixteenth of the average frequency of returns, or some combination of these tendencies. However, constructing a hypothesis on the basis of observations which are assumed not to represent the norm would be fraught with pitfalls. Perhaps a more satisfactory way of incorporating the polaron into a general model for recombination would be to invoke an additional type of structure for the correction of copy-errors. These structures might be spaced several polarons apart, such that one did not happen to occur in the segment studied by Lissouba and Rizet.

\section{SUMMARY}

An extensive analysis of tetrads of Ascobolus immersus in which recombination has occurred between closely-linked spore-colour mutants has been made by Lissouba, Rizet and their co-workers. Recombination between mutants within a short genetic segment was always non-reciprocal, and there was a consistent polarity with regard to the site of the non-reciprocal event. These authors have called this segment a "polaron" and have formulated a hypothesis for the recombination event based on copy-errors which occur during polarised gene replication in meiosis.

The hypothesis proposes that a copy-error may be corrected at the terminal end of the polaron, but in the Ascobolus studies this appeared to happen in only a small fraction of the cases. There is evidence from other forms that meiotic copy-errors are always corrected within a short distance. The polaron model gives a very satisfactory account of the results observed in Ascobolus but does not appear to be sufficient, by itself, to account for the recombination events which occur between homologous chromosomes. 
Acknowledgments.-This paper was written while I was enjoying a fellowship at the John Innes Institute under the sponsorship of the National Science Foundation. I am grateful to Dr J. R. S. Fincham for stimulating discussions during the preparation of the manuscript.

\section{REFERENCES}

CASE, M. E., AND GILES, N. H. 1958a. Evidence from tetrad analysis for both normal and aberrant recombination between allelic mutants in Neurospora crassa. Proc. Nat. Acad. Sci. Wash., 44, 378-39o.

CASE, M. E., AND GILES, N. H. 1958b. Recombination mechanisms at the pan-2 locus in Neurospora crassa. Cold Spring Harbor Symp. Quant. Biol., 23, I 19 -1 35.

Kitani, y., OLIVE, L. S., AND El-ANI, A. s. I962. Genetics of Sordaria fimicola. V. Aberrant segregation at the G locus. Amer. Four. Botany, 49, 697-706.

LIssouBA, P. 1960. Mise en évidence d'une unité génétique polarisée et essai d'analyse d'un cas d'interference negative. Ann. des Sc. Nat., Bot., 12, 641-720. LisSOUBA, P., MOUSSEAU, J., RIZET, G., AND ROSSIGNOL, J. L. 1962. Fine structure of genes in the ascomycete Ascobolus immersus. Advances in Genetics, II , 343-380. MITCHELL, M. B. I 955a. Aberrant recombination of pyridoxine mutants of Neurospora. Proc. Nat. Acad. Sci. Wash., 4I, 2 I 5-220.

MITCHELL, м. в. 1955b. Further evidence of aberrant recombination in Neurospora. Proc. Nat. Acad. Sci. Wash., 4I, 935-937.

RIZET, G., LISSOUBA, P., AND mousseau, J. I 960 . Les mutations d'ascospores chez. l'ascomycete Ascobolus immersus et l'analyse de la structure fine des gènes. Bull. Soc. Francaise Physiol. Vegetale, 6, i 75-193. 